\title{
Estudo por Microscopia Eletrônica do Epitélio de Neovaginas Confeccionadas com Membrana Amniótica e Pesquisa de Receptores para Estrogênios
}

\author{
Electron Microscope Study of the Epithelium of Neovagina Constructed with Amniotic Membrane: \\ Estrogen Receptor Evaluation
}

Mauri José Piazza

\begin{abstract}
RESUMO
Objetivo: verificar pela microscopia eletrônica as alterações ocorridas no âmnio empregado para a construção de neovaginas e a presença de receptores para estrogênio (REc) nesse epitélio.

Métodos: um grupo de 33 pacientes jovens portadoras de agenesia vaginal, em sua maioria amenorréicas, com dificuldade ou impossibilidade de manter atividade sexual, submeteuse à correção cirúrgica da anomalia pela técnica de McIndoe-Banister. Em cada uma das mulheres, a vaginoplastia criou uma cavidade ampla pela dissecção romba do espaço vésico-retal. Um molde de esponja sintética revestido pelo condom e pela membrana amniótica era introduzido e fixado na cavidade criada. No $8^{\circ}$ dia do pós-operatório, o molde era retirado, permanecendo um neoepitélio em formação, oriundo da metaplasia da membrana amniótica. Resultados: a microscopia eletrônica de transmissão (MET) realizada em tecidos obtidos de biópsias das neovaginas mostrou características semelhantes nas três camadas destes epitélios, quer no citoplasma, quer nas organelas celulares em comparação com mulheres normais. Comparou-se a intensidade de coloração dos REc em cortes histológicos do neoepitélio vaginal do grupo de mulheres submetidas à neovaginoplastia pela técnica de McIndoe modificada com mulheres normais no menacme. Os REc apresentaram intensidade distinta nas três camadas da mucosa no grupo de mulheres em que foi elaborada a neovagina com revestimento de membrana amniótica. A análise do neoepitélio vaginal obtido com enxerto de membrana amniótica para correção cirúrgica de agenesia vaginal evidenciou pela MET características de um epitélio vaginal trófico.

Conclusões: o tecido amniótico enxertado sofre um processo de transformação completa $e$ esta mudança foi evidenciada à MET; os graus de intensidade dos REc das diferentes camadas do epitélio vaginal estudado, em cortes histológicos oriundos de mulheres no menacme, são semelhantes aos cortes histológicos obtidos em biópsias de neovaginas revestidas com membrana amniótica.
\end{abstract}

PALAVRAS-CHAVE: Malformações urogenitais. Neovaginoplastia. Membrana amniótica. Receptor para Estrógeno.

\section{Introdução}

O uso do enxerto de pele para revestir a cavidade da neovagina foi inicialmente empregado

Departamento de Tocoginecologia da Universidade Federal do Paraná

Correspondência:

Mauri José Piazza

Rua Francisco Frischmann, 890

80320-250 - Curitiba - Pr por Hepner em 1872. Em 1938, McIndoe e Banister ${ }^{8}$ divulgaram a técnica e os autores usaram enxertos de pele de espessura variável cobrindo um molde vaginal de madeira.

O enxerto de membranas ovulares para construção cirúrgica de neovaginas foi descrito inicialmente por Vidakovic em 1930, mas Brindeau ${ }^{3}$ a tornou conhecida por seus estudos em 1934 e 1946. A partir de 1986, procuramos aperfeiçoar a técnica cirúrgica com o emprego de enxertos de 
membrana amniótica e procedimentos dilatadores posteriores com moldes rijos, tentando obter melhores resultados. A incorporação total destes enxertos na área dissecada do espaço vésico-retal e sua transformação precoce numa mucosa vaginal é tema de análise nesta pesquisa.

\section{Pacientes e Métodos}

Foram selecionadas 33 pacientes portadoras de agenesia vaginal que haviam sido atendidas no ambulatório de Endocrinologia Ginecológica do Serviço de Ginecologia do Hospital de Clínicas da UFPR.

Em época adequada e num período de 60 a 90 dias antes do inicio da atividade sexual, estas pacientes foram submetidas à neovaginoplastia pela técnica de $\mathrm{McIndoe}^{7}$, empregando-se enxerto com membrana amniótica, anteriormente obtida.

Essa técnica cirúrgica foi realizada em 33 pacientes, dentre as quais 6 eram portadoras de quadro de pseudo-hermafroditismo masculino. Nestas não foi avaliada a expressão dos receptores (REc), devido à resposta irregular aos estímulos dos androgênios e estrogênios. A presença de receptores de estrogênio foi estudada em 20 pacientes com agenesia vaginal.

De 10 pacientes (indicadas por asterisco na Tabela 1) foram colhidos fragmentos de neo-epitélio vaginal, após 60-90 dias do ato cirúrgico de neovaginoplastia, para estudo por microscopia eletrônica de transmissão (MET).

Estes fragmentos foram lavados em tampão de cacodilato $0,2 \mathrm{M}$ e em solução aquosa de tetróxido de ósmio a $1 \%$. A seguir, os tecidos passaram por 3 lavagens em água destilada e foram deixados por 24 horas em acetato de uranila a $2 \%$. Os fragmentos foram novamente lavados 3 vezes com água destilada e desidratados em soluções de concentrações de álcool progressivamente crescentes de $70 \%, 80 \%, 90 \%$ e $100 \%$, por 10 minutos em cada solução. Logo após, o material foi imerso em solução de óxido de propileno a $99 \%$ por período de 2 a 10 minutos e, a seguir, em misturas de óxido de propileno com resina de araldite na proporção de $3: 1$ e de $1: 1$ por 60 minutos cada. Após permanecer 24 horas em resina de araldite pura, em agitador, os tecidos foram incluídos em nova mistura araldite e cortados no ultramicrótomo tipo Reichert-Jung.

A seguir, estes cortes ultrafinos foram corados com citrato de chumbo e acetato de uranila a $2 \%$ e observados em microscópio eletrônico Philips EM300.
Tabela 1 - Características do grupo de pacientes com agenesia de vagina - avaliação da intensidade dos REc nas neovaginas.

\begin{tabular}{|c|c|c|c|c|}
\hline \multirow[t]{2}{*}{ CASO } & \multirow{2}{*}{$\begin{array}{c}\text { IDADE } \\
\text { (anos) }\end{array}$} & \multicolumn{3}{|c|}{ REc } \\
\hline & & $\mathrm{CP}$ & $\mathrm{Cl}$ & CS \\
\hline 01 & 36 & +++ & +++ & + \\
\hline 02 & 19 & +++ & ++ & + \\
\hline 03 & 21 & +++ & +++ & 0 \\
\hline * 04 & 22 & +++ & +++ & + \\
\hline 05 & 28 & +++ & ++ & + \\
\hline 06 & 17 & ++ & ++ & + \\
\hline 07 & 24 & +++ & ++ & + \\
\hline 08 & 19 & +++ & 0 & + \\
\hline 09 & 34 & +++ & +++ & + \\
\hline 10 & 19 & +++ & +++ & 0 \\
\hline 11 & 16 & ++ & 0 & + \\
\hline 12 & 22 & +++ & ++ & 0 \\
\hline 13 & 20 & +++ & +++ & + \\
\hline * 14 & 20 & + & ++ & 0 \\
\hline 15 & 24 & +++ & +++ & 0 \\
\hline * 16 & 18 & +++ & +++ & 0 \\
\hline * 17 & 28 & +++ & ++ & + \\
\hline 18 & 18 & +++ & ++ & 0 \\
\hline * 19 & 18 & ++ & ++ & + \\
\hline 20 & 23 & +++ & ++ & + \\
\hline 21 & 19 & - & - & - \\
\hline 22 & 19 & - & - & - \\
\hline 23 & 27 & - & - & - \\
\hline 24 & 22 & - & - & - \\
\hline 25 & 18 & - & - & - \\
\hline 26 & 23 & - & - & - \\
\hline * 27 & 18 & - & - & - \\
\hline * 28 & 18 & - & - & - \\
\hline 29 & 20 & - & - & - \\
\hline * 30 & 21 & - & - & - \\
\hline * 31 & 19 & - & - & - \\
\hline 32 & 24 & - & - & - \\
\hline * 33 & 26 & - & - & - \\
\hline
\end{tabular}

* = Pacientes submetidas a biópsias para estudo de MET

Pacientes de $n^{0} 21$ a $33=$ REc não determinados

CP - camada profunda

$\mathrm{Cl}$ - camada intermediária

CS - camada superficial

\section{Receptores de estrogênio}

Para avaliação da presença de REc os fragmentos do epitélio vaginal e de membranas amnióticas foram coletados em frascos contendo álcool etílico absoluto e fixados em álcool. Após 24 horas, foram cortados em pedaços menores e a seguir processados em um processador automático de tecidos Autotechnicon. Neste processador, os cortes foram desidratados em uma série de 
concentração crescente de soluções de etanol (70\%, $80 \%, 90 \%$ e $100 \%$ ), com banhos consecutivos de uma hora cada um.

A seguir, as peças foram diafanizadas em xilol (3 banhos de 2 horas cada) e impregnadas com parafina fundida a $60^{\circ} \mathrm{C}$ ( 2 banhos de 4 horas cada), sendo então incluídas em blocos de parafina.

Para o estudo imunocitoquímico, utilizou-se o método PAP (peroxidase-antiperoxidase) conforme Sternberger ${ }^{14}$. Para a utilização deste método, foram empregados kits produzidos pela Biogenex Laboratories, com anticorpos capazes de reconhecer no citoplasma a presença do receptor para o E2, que é uma proteína especifica de $29 \mathrm{kDa}$.

As lâminas foram previamente tratadas em solução contendo metanol e água oxigenada a 3\%, com a finalidade de inibir a peroxidase endógena. Os cortes foram delimitados com lápis para vidro, a fim de se evitar que o anticorpo aplicado sobre o tecido se espalhasse. Os cortes foram incubados com anticorpo monoclonal específico para o estrogênio, em uma câmara úmida por um período de 30 minutos à temperatura ambiente.

Com o intuito de demonstrar a imunorreação, as lâminas foram incubadas com uma solução de diaminobenzidina (DAB), durante 15 a 40 minutos, que funciona como cromógeno. Em estudo anterior realizado por Piazza ${ }^{12}$, o cromógeno usado foi o dietilcarbazol.

Para a interpretação dos resultados obtidos com a observação ao microscópio óptico, foi convencionada a seguinte sistematização, a partir da intensidade da coloração das granulações citoplasmáticas das células, conforme padronização proposta pelo Laboratório Biogenex ${ }^{14}$ :

\begin{tabular}{lcl}
\hline Ausente & 0 (zero) & ausente \\
\hline Coloração amarelo-clara & + & intensidade discreta \\
Coloração amarela & ++ & intensidade moderada \\
Coloração amarelo-acastanhada & +++ & intensidade forte \\
Coloração marrom escura & ++++ & intensidade acentuada \\
\hline
\end{tabular}

\section{Resultados}

Neste grupo de 33 pacientes, evidenciam-se 2 subgrupos. No subgrupo 1 foram estudadas 27 pacientes portadoras da sindrome de RokitanskyKuster-Hauser, todas com a cromatina sexual de Barr positiva. No subgrupo 2, foram incluídas 6 pacientes com cromatina sexual negativa e com diagnósticos de pseudo-hermafroditismo masculino.

Foi avaliada também neste grupo de pacientes a possibilidade de coexistirem, associadas à agenesia vaginal, anomalias do aparelho urinário, dados expressos na Tabela 2.

TABELA 2 - Anomalias no aparelho urinário presentes em pacientes com agenesia de vagina.

\begin{tabular}{lrr}
\hline Urografia & $\mathrm{n}$ & $\%$ \\
\hline Normal & 18 & 54,5 \\
Rim pélvico & 5 & 15,1 \\
Rim dextroposto & 3 & 9,1 \\
Rim E cruzado; D normal & 2 & 6,1 \\
Sem informação & 5 & 15,2 \\
Total & 33 & 100,0 \\
\hline
\end{tabular}

Utilizando MET foram analisadas biópsias de 10 pacientes (Tabela 1: casos de $\mathrm{n}^{\circ} 4,14,16,17$, $19,27,28,30,31$ e 33) que haviam sido submetidas à neovaginoplastia. O neo-epitélio vaginal apresentava à ultramicroscopia aspecto similar ao da mucosa normal, observando-se córion, membrana basal e epitélio pavimentoso. Neste epitélio destacam-se células da camada profunda, intermediária e superficiais sendo que as características citoplasmáticas e das organelas celulares eram similares ao epitélio normal.

Os REc foram avaliados em 20 pacientes do subgrupo 1. A presença de REc não foi avaliada nas pacientes do subgrupo 2 .

A presença dos REc no epitélio das neovaginas foi evidenciada em graus variáveis nas diversas camadas da mucosa (Tabela 3). Mostrouse nestes fragmentos de epitélio a existência distinta de várias camadas na mucosa vaginal, contendo receptores citosólicos de intensidade praticamente idêntica.

Tabela 3 - Intensidade da coloração para REc nas camadas profunda, intermediária e superficial do neoepitélio vaginal ( $\mathrm{n}=20$ pacientes).

\begin{tabular}{lcrcccc}
\hline Intensidade & \multicolumn{2}{c}{ Profunda } & \multicolumn{2}{c}{ Intermediária } & \multicolumn{2}{c}{ Superficial } \\
\cline { 2 - 7 } & $\mathrm{n}$ & $\%$ & $\mathrm{n}$ & $\%$ & $\mathrm{n}$ & $\%$ \\
0 & 0 & - & 2 & 10,0 & 7 & 35,0 \\
+ & 1 & 5,0 & 0 & - & 13 & 65,0 \\
++ & 3 & 15,0 & 10 & 50,0 & 0 & - \\
+++ & 16 & 80,0 & 8 & 40,0 & 0 & - \\
\hline
\end{tabular}

\section{Discussão}

As mais diversas técnicas foram aplicadas nas pacientes portadoras de agenesia vaginal, com o intuito de obter-se uma conveniente resolução desta anormalidade. Todos os estudos tentaram 
conseguir com diversos tecidos um canal vaginal epitelizado, trófico e propício a uma atividade sexual adequada. O emprego de enxertos de pele preconizados desde 1938 por McIndoe e Banister ${ }^{8}$ propiciaram melhoria da técnica cirúrgica e resultados satisfatórios nas pacientes com agenesia vaginal.

A observação posterior destas pacientes revelava que na vagina ocorria um processo apenas parcial de transformação de pele em mucosa ${ }^{2}$. Permaneciam áreas epidermizadas dentro da cavidade vaginal, revelando-se locais com pele de aspecto espessado com crescimento de pêlos. Também no local de onde era removido o fragmento de pele para o enxerto, geralmente a face externa da coxa ou das nádegas, havia um retardo da cicatrização ou mesmo a ocorrência de cicatrizes queloidianas.

Observou que a membrana amniótica enxertada era capaz de induzir o surgimento de um neo-epitélio na cavidade vaginal recém aberta. Esta observação estava concorde com os estudos de Dhall ${ }^{4,5}$ e de Asworth et al. ${ }^{1}$ mostrando que o âmnio tem também condições antigênicas favoráveis, não ocorrendo processo de rejeição contra esta membrana.

Em nosso meio tem sido relatado desde 1989 o uso de fragmentos de membrana amniótica para a correção de agenesias de vagina e também nas ginatresias vaginais ${ }^{9,10,11,13,15}$

Com o intuito de observar-se o processo de transformação a que foi submetido o âmnio, foram realizados estudos ultra-estruturais por microscopia eletrônica de transmissão. $\mathrm{O}$ aspecto por MET do âmnio permitiu observar que esse epitélio é formado por uma única camada de células cilindricas ou cúbicas que repousam sobre um córion composto por fibrilas de tecido conjuntivo frouxo que estão dispostas em aspecto ondulado e paralelo à superficie. Pode-se observar que sucedeu uma total transformação do epitélio do âmnio, que é formado por uma só camada de células, em um epitélio poliestratificado, trófico e com as características de um epitélio vaginal normal.

A determinação citoplasmática dos REc também realizada neste estudo visou evidenciar sua intensidade nas diferentes camadas deste neoepitélio. Por meio destas avaliações, foi possivel comparar o grau de intensidade dos REc nas vaginas normais em estudo procedido por Piazza ${ }^{12}$ com o grupo das pacientes com agenesia vaginal, cujas neovaginas foram construidas com membrana amniótica, sendo similares os resultados nestes 2 grupos.

Como conclusões observamos que o tecido amniótico enxertado sofre um processo de transformação completa e esta mudança foi evidenciada à MET. A membrana amniótica empregada para recobrir a neovagina sofre um processo metaplásico que a torna semelhante à mucosa vaginal normal após 60 a 90 dias do ato cirúrgico; os graus de intensidade de coloração dos REc das diferentes camadas do epitélio vaginal, em cortes histológicos oriundos de mulheres no menacme, são semelhantes aos cortes histológicos obtidos em biópsias de neovaginas revestidas com membrana amniótica.

\section{SUMMARY}

Purpose: to verify changes in amnion epithelia after neovaginoplasty and the presence of estrogen receptor in this tissue using electron microscopy (TEM).

Methods: a group consisting of 33 young patients with vaginal agenesy, most of them amenorreic, either incapable or having difficulty to adequately perform sexual activity, underwent surgical correction of the anomaly by the McIndoe-Banister technique. In each woman, a cavity was created through an opening of the vesicorectal space. A mold made of artificial sponge with a condom recovered by amniotic membrane was introduced into the cavity. After eight days, the mold was removed, leaving a developing neoepithelium from the amniotic membrane.

Results: The TEM conducted in samples of tissue obtained from neovaginas showed similar results in all three layers of these epithelia, either in the cytoplasm or the cellular microstructures in comparison with normal women. The intensity of staining of the estrogen receptors on the vaginal neoepithelium of the group of women who underwent the surgical procedure was similar to that of normal women. The estrogen receptors were heterogeneously distributed in the three layers of the tissue in all women. The analysis of the vaginal neoepithelium obtained from amniotic membrane revealed, through the TEM, all the characteristics of a regular vaginal epithelium.

KEY WORDS: Urogenital malformation, Neovaginoplasty. Amniotic membrane. Estrojen receptor.

\section{Referências}

1. Asworth MF, Morton KE, Dewhurst J, Lilford RJ, Bates RG. Vaginoplasty using amnion. Obstet Gynecol $1986 ; 67: 433-43$.

2. Barberini F, Vizza E, Montanino M, Marcoccia S, Montanino G. Vaginal reconstruction by skin grafts; a scanning electron microscopic evaluation. Anat Anz 1992;174,6:517-22.

3. Brindeau A. Création d'un vagin artificiel à l' aide des membranes ovulaires d' un oeuf à terme. Gynecol Obstet 1934;29:385-92. 
4. Dhall K. Amnion graft for treatment of congenital absence of the vagina. Br J Obstet Gynaecol 1984;91:279-82.

5. Dhall K. Congenital absence of the vagina a simple surgical procedure for its relief. Aust NZ J Obstet Gynaecol 1987;27:240-4.

6. Lodovici O. Neovaginoplastia metodizada no tratamento da ausência congênita da vagina.. Tese (Livre-Docência). São Paulo: Faculdade de Medicina da Universidade de São Paulo; 1966.

7. McIndoe AH. The application of cavity grafting. Surgery $1937 ; 1: 535$.

8. McIndoe AH, Banister JB. An operation for the cure of congenital absence of the vagina. J Obstet Gynaecol 1938;45:490-4.

9. Moura MD, Ferriani RA, Sá MFS, Wanderley MS, Leite, $\mathrm{SP}$, Soares, FA. Epitelização vaginal com membrana amniótica em neovaginoplastia. Rev Bras Ginecol Obstet 1994;16,3-4:135-40.

10. Piazza MJ, Teixeira AC, Carreira C, Siviero C, Coelho
A. Tratamento da ausência congênita da vagina: estudo de 60 casos. Rev Bras Ginecol Obstet $1989 ; 11: 177-82$.

11. Piazza MJ, Teixeira AC. Neovaginoplastia pela técnica de McIndoe com o emprego de membrana amniótica: estudo de 15 pacientes. Rev Bras Ginecol Obst 1992;14,5:224-6.

12. Piazza MJ. Avaliação da intensidade dos receptores de estrogênio por método imunocitoquímico em biópsias da mucosa vaginal de mulheres no menacme. Tese (Mestrado). Curitiba: Universidade Federal do Paraná; 1993.

13. Salvatore CA, Lodovici O. Vaginal agenesis. Acta Obstet Gynecol Scand 1978;57:89-94.

14. Sternberger LA. 1979. Immunocytochemistry. New Jersey: Prentice Hall Inc.

15. Wehba S, Carvalho CRN, Ferreira JAS, Suda E. Ausencia congênita de vagina:correção cirúrgica com peritoneo pélvico. J Bras Ginecol 1978;85:131-6. 